\section{Pluralismo evolutivo e o ideal de unificação da biologia}

\section{Evolutionary pluralism and the ideal of a unified biology}

\author{
Leonardo Augusto Luvison Araújo \\ ' Pesquisador de pós-doutorado, Faculdade de Educação/ \\ Universidade de São Paulo. \\ São Paulo - SP - Brasil \\ orcid.org/0000-0003-0386-7745 \\ leonardo_luvison@hotmail.com
}

\footnotetext{
Claudio Ricardo Martins dos Reis ${ }^{i i}$

ii Professor, Instituto de Biologia/Universidade Federal da Bahia. Salvador - BA - Brasil

orcid.org/0000-0002-4214-530X

claudiormreis@gmail.com
}

Recebido em 11 mar. 2019.

Aprovado em 12 ago. 2019.
ARAÚJO, Leonardo Augusto Luvison;

REIS, Claudio Ricardo Martins dos.

Pluralismo evolutivo e o ideal de unificação da biologia. História, Ciências, Saúde - Manguinhos, Rio de Janeiro, v.28, n.2, abr.-jun. 2021, p.393-411.

\section{Resumo}

A evolução biológica é frequentemente considerada um eixo central e unificador da biologia. $\mathrm{O}$ artigo discute aspectos históricos desse ideal de unificação, bem como os seus sinais de desintegração entre os anos 1960 e 1980. Argumentamos que apesar das novas propostas de síntese do conhecimento biológico, a biologia evolutiva contemporânea é caracterizada por um pluralismo. Os principais pontos a favor do pluralismo evolutivo são discutidos, e algumas consequências dessa perspectiva são apresentadas, particularmente em relação ao ideal de unificação da biologia. Por fim, defendemos um pluralismo evolutivo crítico do ideal de unificação como um objetivo da ciência, mas ainda favorável a integrações locais.

Palavras-chave: evolução biológica; história da biologia; unificação da biologia; pluralismo.

\section{Abstract}

Biological evolution is often regarded as a central and unifying axis of biology. This article discusses historical aspects of this ideal of unification, as well as signs of its disintegration from the 1960s to 1980s. We argue that despite new proposals for the synthesis of biological knowledge, contemporary evolutionary biology is characterized by pluralism. The main points in favor of evolutionary pluralism are discussed and some consequences of this perspective are presented, particularly in terms of the ideal of a unified biology. Finally, we defend an evolutionary pluralism that critiques the ideal of unification as a scientific objective, but still favors local integrations.

Keywords: biological evolution; history of biology; unification of biology; pluralism. 
A evolução biológica é frequentemente considerada um eixo central e unificador da biologia (Smocovitis, 1996). Considera-se que a chamada síntese evolutiva - movimento que começou nas primeiras décadas do século XX e se consolidou no final da década de 1940 - seja um marco importante na promoção de uma biologia unificada (Largent, 2009).

A síntese evolutiva remete aos primórdios da genética de população, sendo caracterizada por uma mobilização acadêmica em torno da ressignificação do darwinismo em bases genético-mendelianas (Mayr, 1980). Uma série de novidades empíricas e teóricas que surgiram entre os anos 1912-1918 tornou-se a herança mendeliana central para o estudo da variação biológica e das causas evolutivas (Provine, 2001, p.109). Uma vez que a transmissão de fatores hereditários é governada por regras estatísticas aplicáveis às populações, a explicação genética também necessariamente tinha de ser estatística. Por isso, técnicas estatísticas desenvolvidas pelos biometristas foram parcialmente modificadas de 1920 a 1930, permitindo uma aproximação entre mendelismo, darwinismo e biometria (Provine, 2001, p.130). Essa construção teórica foi conduzida, em grande medida, por geneticistas de população como Ronald Fisher (1890-1962), John Bourdon S. Haldane (1892-1964) e Sewall Wright (1899-1988).

A incorporação dos preceitos desenvolvidos pela genética de população em diferentes disciplinas biológicas ocorreu entre 1937 e 1947, em boa parte como decorrência dos esforços de Theodosius Dobzhansky (1900-1975). O objetivo de Dobzhansky era construir um terreno no qual as áreas heterogêneas e fragmentadas da biologia pudessem ser "ligadas" a partir da genética de população (Smocovitis, 1996).

Apesar de os autodenominados "arquitetos da síntese" discordarem em temas evolutivos mais circunstanciais, como em relação às interações gênicas, à eficiência da seleção natural em grandes e pequenas populações e ao papel do acaso na evolução, os autores concordavam que a biologia evolutiva estava baseada na estrutura matemática da genética de população, que criou um quadro geral capaz de unificar diversos fenômenos em uma síntese teórica relativamente simples. Desse modo, distintos fenômenos, disciplinas e organismos biológicos passaram a ser abordados a partir desse arcabouço teórico (Stoltzfus, 2017).

De modo não casual, esse movimento pela unificação da biologia ocorreu concomitantemente às intensas atividades do círculo de Viena, movimento intelectual que visava, entre outros aspectos, a uma ciência formalizada e unificada (Hahn, Neurath, Carnap, 1986, p.10). A unidade da ciência na proposta do círculo de Viena é caracterizada pela crença de que todas as ciências - físicas, biológicas e sociais - podem ser traduzidas em sentenças que tratam apenas de objetos físicos, constituindo logicamente uma linguagem, a chamada linguagem fisicalista (Cunha, 2018). Se na década de 1920 a crença na unidade da ciência foi um dos princípios fundamentais dos positivistas lógicos do círculo de Viena, nas ciências biológicas esse período testemunhou um realinhamento disciplinar para a unificação da biologia (Smocovitis, 1992, p.3). Além dos ideais de unificação e formalização - matemática, no caso da síntese evolutiva, e lógica, no caso do círculo de Viena -, outro elemento comum aos dois movimentos foi a tendência de expurgar elementos metafísicos que não possuem lastro na experiência humana.

Segundo Hahn, Neurath e Carnap (1986), a biologia era uma ciência especialmente "contaminada" com alegações metafísicas: 
Os metafísicos sempre distinguiram com predileção a biologia como um domínio especial. Isto se expressou na doutrina de uma força vital especial, no vitalismo. Os modernos defensores desta doutrina esforçam-se em conduzi-la da forma obscura e vaga do passado a uma versão clara, do ponto de vista conceitual. No lugar da força vital, aparecem as 'dominantes' (Reinke, 1899) ou 'enteléquias' (Driesch, 1905). Tais conceitos são rejeitados como metafísicos pela concepção científica do mundo, uma vez que não satisfazem a exigência de redutibilidade ao dado (Hahn, Neurath, Carnap, 1986, p.16; destaques no original).

Na virada para o século XX, biólogos de diferentes áreas de pesquisa lançavam mão de mecanismos intencionais de evolução, o que os autores do círculo de Viena consideravam especulações metafísicas. Em consonância com o círculo de Viena, a síntese evolutiva foi um esforço de unificação concentrado em tornar a evolução uma "ciência positiva", e, para tal intento, buscou empregar métodos experimentais baseados em evidências empíricas e com resultados generalizáveis em termos matemáticos. Expurgada de elementos metafísicos inaceitáveis, a síntese evolutiva buscou ser não apenas a abordagem estritamente científica para a biologia evolutiva, mas para a biologia como um todo, unindo e alicerçando as práticas heterogêneas dessa ciência (Smocovitis, 1996; Ferreira, Selles, 2005).

Tal projeto de unificação proporcionou um avanço no diálogo entre diferentes áreas da biologia - apesar dos ouvidos surdos para algumas disciplinas biológicas. Os arquitetos da síntese evolutiva contribuíram para a institucionalização da biologia, organizando conferências, revistas e ambientes institucionais em que especialistas de diferentes áreas puderam entrar em contato e formar uma comunidade científica relativamente coesa. Um exemplo emblemático foi a Conferência sobre genética, paleontologia e evolução, em Princeton (1947). Essa conferência inaugurou a Society for the Study of Evolution, reunindo alguns dos principais evolucionistas da época. Ao criar essas condições institucionais, evolucionistas de diferentes campos da biologia puderam discutir e compartilhar suas investigações. Delisle (2011, p.51) caracteriza tais condições institucionais para a unificação da biologia como uma genuína "síntese sociológica".

Mas ainda que a dimensão sociológica da síntese evolutiva tenha sido bem sucedida, o que podemos dizer dos seus aspectos epistemológicos e compromissos metafísicos fundamentais? Para Sahotra Sarkar (2004, p.1217), a referência ao conceito de síntese implicaria, no mínimo, a união de duas ou mais estruturas científicas independentes como explicações, modelos, teorias e disciplinas -, reunidas de forma a fortalecerem-se mutuamente em uma estrutura integrada. Para o autor, em uma síntese também seria desejável paridade epistêmica, de modo a distingui-la de outras mudanças científicas, como a redução.

Muitos filósofos e historiadores da biologia evolutiva, no entanto, discutem as limitações de considerar a relação entre as estruturas científicas da síntese evolutiva em termos de síntese (Gould, 1983; Provine, 1992; Smocovitis, 1996; Sarkar, 2004, 2017; Delisle, 2011). Se pensarmos em aspectos disciplinares, por exemplo, torna-se difícil considerar uma relação paritária entre as diferentes disciplinas biológicas na síntese evolutiva, uma vez que as explicações para os fenômenos evolutivos passaram a ser dadas em termos de processos microevolutivos que, em última instância, estão baseados na genética de população (Sarkar, 
2004). Nesse sentido, a genética de população teria prioridade explicativa sobre outras disciplinas.

Outra crítica apresentada para o ideal de unificação da biologia por meio da síntese evolutiva é a pouca participação de disciplinas biológicas relevantes, como morfologia, paleontologia e embriologia (Smocovitis, 1996). As explicações evolutivas buscadas por autores desses campos entravam em conflito com aquelas apresentadas pelos arquitetos da síntese evolutiva (Amundson, 2005). Dessa forma, a proposta de unificação da biologia a partir da síntese evolutiva já dava sinais de suas limitações desde a sua consolidação.

\section{Os sinais de desintegração da síntese evolutiva}

A síntese evolutiva estabeleceu alguns pressupostos comuns que permitiram aos biólogos de diferentes áreas trabalhar juntos, particularmente em relação aos problemas evolutivos. Alguns desses pressupostos são o "genecentrismo", o gradualismo estrito, a extrapolação de explicações microevolutivas para padrões macroevolutivos e a primazia da seleção natural (Laland et al., 2015, p.2). Isso significa que, para a síntese evolutiva, a herança genética constitui o único sistema de herança evolutivamente relevante; as mudanças evolutivas ocorrem somente com pequenos passos, levando ao gradualismo evolutivo; os padrões macroevolutivos são explicados pelo acúmulo de eventos microevolutivos, por meio de processos populacionais; e há um privilégio da seleção natural na explicação das mudanças evolutivas.

Entre os anos 1960 e 1980, contudo, diferentes avanços empíricos e teóricos da própria biologia evolutiva desafiaram esses elementos centrais da síntese evolutiva. Segundo Stoltzfus (2017, p.14), a emergência da evolução molecular foi o primeiro sinal visível de "desintegração" da síntese evolutiva. As pesquisas com evolução molecular nos anos 1960 retomaram a força da deriva genética e lançaram uma série de desafios para a primazia da seleção natural.

Esse tema era controverso mesmo para os arquitetos da síntese evolutiva, sendo que, até os anos 1930, a deriva genética recebeu frequentemente um papel predominante como causa da mudança fenotípica (Gould, 1983). A partir dos anos 1940, no entanto, a seleção natural passa a ser considerada mais enfaticamente o principal mecanismo da mudança evolutiva.

As pesquisas moleculares dos anos 1960, por outro lado, mostraram um grande papel da deriva genética no estoque de variantes genéticas das espécies. A teoria neutra da evolução molecular de Kimura (1968) considerava que grande parte das mutações não tem um efeito fenotípico perceptível e, dessa forma, persiste nas populações por deriva, e não por ação da seleção natural. As pesquisas moleculares apontaram certo "paradoxo" molecularmorfológico: o que era verificado em nível morfológico, e priorizado pela síntese evolutiva, não parecia se adequar ao nível molecular.

Pouco tempo depois das pesquisas de Motoo Kimura (1968), Gould e Eldredge (1972) apresentaram a teoria do equilíbrio pontuado, desafiando outro pressuposto da síntese evolutiva - o gradualismo estrito. Os autores inseriram a interpretação de um padrão diferente para algumas linhagens, em vista do registro fóssil. Gould e Eldredge argumentaram que determinadas espécies apresentam certa estabilidade no tempo 
("inalteradas" morfologicamente), seguidas por um período de rápida divergência. Esse padrão não seria decorrente de uma falha no registo fóssil, como pressupunha o gradualismo estrito, mas de um processo genuinamente evolutivo de estase que é seguido, "subitamente" na próxima formação de rocha sedimentar, de uma mudança pontuada na morfologia, com a origem de nova espécie proximamente aparentada.

No final dos anos 1970, Gould ainda elabora críticas ferrenhas aos outros pressupostos centrais da síntese evolutiva. Em parceria com o geneticista Richard Lewontin, publica um artigo intitulado "The spandrels of San Marcos and the Panglossian paradigm: a critique" (Gould, Lewontin, 1979). O artigo contém duas metáforas interessantes, que nos ajudam a entender suas críticas - os spandrels da basílica de São Marcos e o "paradigma" panglossiano. Spandrels são espaços cônicos entre os arcos que sustentam um telhado em forma de cúpula, como o encontrado na basílica de São Marcos, na Itália. Esses espaços estão maravilhosamente pintados, embora não tenham sido projetados para essa finalidade artística. A simetria e a coerência dos spandrels podem levar a inferir que eles são a razão de todo o sistema de arcos e cúpulas que os cerca. No entanto, eles são um subproduto arquitetônico no emprego de arcos para apoiar uma sala em forma de cúpula. Por isso, os spandrels só são explicados como um subproduto da construção, não sendo um elemento projetado para qualquer finalidade, seja ela arquitetônica ou artística.

Gould e Lewontin usam esse exemplo para se referir a determinado modo, que eles consideram problemático, de interpretar os seres vivos. Muitos biólogos dividem os organismos em partes e atribuem a cada uma delas determinada função, quando, em verdade, é preciso procurar as explicações evolutivas para o organismo integrado, complexo e indivisível. Para entender os spandrels é preciso considerar toda a estrutura arquitetônica que o circunda, caso contrário podemos erroneamente atribuir uma função original a essa estrutura. Quando os biólogos dividem os organismos em partes e atribuem função a cada uma delas, eles podem incorrer no mesmo erro de um observador que encara os spandrels como um projeto original da basílica.

A síntese evolutiva incorreria em erro análogo ao procurar uma origem adaptativa para praticamente todas as características dos organismos. Com isso, essa abordagem não visualiza a possibilidade de que muitas características podem ser subprodutos do desenvolvimento, mesmo que adquiram uma determinada função ao longo do processo evolutivo. Assim como os spandrels são subprodutos arquitetônicos e acabaram recebendo uma função artística na basílica, os seres vivos também possuem subprodutos fenotípicos do seu desenvolvimento e evolução, que não foram "projetados" (selecionados) para uma característica funcional em sua origem.

A abordagem selecionista e atomista é ainda apelidada de "panglossiana" por Gould e Lewontin (1979), em referência a um personagem da obra Cândido, ou o otimismo, de Voltaire - o doutor Pangloss. Esse personagem tem a crença de que as coisas estão no mundo para o melhor dos fins. Dizia o doutor Pangloss que "as coisas não podem ser de outra forma: pois tendo tudo sido feito para um fim determinado, tudo se dirige para o melhor dos fins. Notai como os narizes foram feitos para levar óculos; e com efeito temos óculos. As pernas foram manifestamente instituídas para ser calçadas, e com efeito temos calças" (Voltaire, 2006, p.10). 
A metáfora biológica do "paradigma panglossiano" remete ao ideal de que a seleção natural deve ter restrições mínimas, de modo que a adaptação seria a causa primária de toda forma, função e comportamento exibido pelos seres vivos. Desse modo, ao crer na onipotência da seleção natural como uma idealização de um "design ótimo" dos seres vivos, esse paradigma se aproxima de uma visão panglossiana ingênua e funcional do mundo.

Tais críticas eram endereçadas aos evolucionistas que se apressam em assumir funcionalidade para qualquer característica encontrada nos seres vivos, criando hipóteses adaptativas e explicando a sua existência em um modelo seletivo. Essa seria uma prática de propor meramente histórias adaptativas para explicar a existência de características funcionais, sem necessariamente testar empiricamente essa hipótese ou considerar outros cenários. ${ }^{1}$

Essas explicações, ditas "adaptacionistas", eram consideradas meras historietas (justso-stories). Como afirma Abrantes (2011, p.20), "a tese adaptacionista a respeito do poder explicativo da seleção natural (à exclusão de outros mecanismos) não seria testável; e as historietas geradas com base nessa tese tampouco poderiam ser submetidas à prova empírica".

É importante deixar claro que as críticas de Gould e Lewontin não visavam minar as explicações por seleção natural. O que eles visavam era explicitar pontos cegos da teoria evolutiva que sobrevalorizavam explicações por seleção natural e excluíam explicações alternativas. No artigo de 1979, os autores apontam que os biólogos devem ao menos considerar mais seriamente a deriva genética, as restrições relacionadas aos processos de desenvolvimento, as restrições estruturais e relacionadas à história filogenética dos seres vivos.

As restrições relacionadas aos processos de desenvolvimento e as restrições estruturais e relacionadas à história filogenética não são consideradas no programa adaptacionista da síntese evolutiva, porque essa abordagem é baseada em uma biologia de partes e genes, mas não de organismos. Os organismos são entidades integradas, de modo que muitas das características neles observadas são resultantes de restrições estruturais que afetam as interações dos elementos que formam o todo. O adaptacionismo é considerado uma posição funcionalista, e foi, por isso, criticado por Gould e Lewontin, que apontaram para a necessidade de privilegiar outras explicações evolutivas plausíveis, sobretudo aquelas com caráter estruturalista.

Funcionalismo e estruturalismo podem ser encarados como balizamentos filosóficos fundamentais que distinguem diferentes propostas de investigação (Abrantes, 2011). A separação teórica entre os estudos da forma e função levou muitos autores a postular a ideia de uma dicotomia entre estruturalismo e funcionalismo na história do pensamento biológico. De um lado, os estruturalistas sustentam que as mudanças evolutivas são modificações da forma, e, como a morfologia é produto do desenvolvimento, o estudo da evolução biológica deveria passar necessariamente pelo estudo dos processos de modificações ontogenéticas. De outro lado, os funcionalistas sustentam que as mudanças evolutivas são modificações essencialmente funcionais, e que os organismos podem ser particionados de modo a associar cada parte a uma função distinta. Na medida em que a embriologia teve um papel limitado na síntese evolutiva, entende-se por que as abordagens estruturalistas tiveram um impacto menor no pensamento evolutivo (Amundson, 2005, p.27).

Diante dessas críticas nas décadas de 1960 e 1970, ao longo dos anos 1980 alguns autores buscaram propor novas formas de síntese que pudessem solucionar as alegadas 
ausências na síntese evolutiva e, assim, levar a uma maior unificação da biologia. Alguns exemplos são os trabalhos de Gould (1980), Robert Reid (1985) e Niles Eldredge (1985). Tais propostas arrefeceram nos anos 1990, mas a partir da primeira década dos anos 2000 elas retomaram força com a proposta da chamada síntese evolutiva estendida (Pigliucci, Müller, 2010).

Atualmente, essa proposta está em debate na comunidade científica. Um exemplo é o artigo publicado recentemente "Does evolutionary theory need a rethink"? (Laland et al., 2014), onde evolucionistas divergem sobre quais processos devem ser considerados fundamentais na evolução. Assinam esse artigo biólogos evolucionistas que lideram alguns dos principais grupos de pesquisa no mundo. Os autores estão divididos entre a ideia de que sem uma síntese evolutiva estendida a biologia evolutiva negligencia processos-chave e antagonicamente, a posição de que a teoria evolutiva contemporânea acomoda as novidades empíricas e teóricas. Este último grupo defende que, em última análise, está tudo bem com a teoria evolutiva-padrão, uma vez que ela sempre foi capaz de incorporar inovações e extensões de diferentes campos. Afinal, longe de ficar presa ao passado, a teoria evolutiva atualmente se mostra um vibrante campo de pesquisa (Laland et al., 2014, p.163).

O futuro desse debate é incerto, e, como contemporâneos de tal processo histórico, ainda não temos uma visão clara de suas tendências e de seus desdobramentos. Independentemente do posicionamento dos autores no artigo supracitado - se a síntese evolutiva realmente negligencia processos evolutivos ou os acomoda em seu arcabouço -, os evolucionistas admitem avanços empíricos e teóricos que têm apontado para uma pluralidade na biologia evolutiva (Futuyma, 2017). A biologia evolutiva contemporânea compreende múltiplos quadros conceituais coexistentes e perspectivas que discordam sobre a natureza e o escopo da teoria evolutiva (Eldredge, 1985; Fábregas-Tejeda, Vergara-Silva, 2018). A evolução dos seres vivos é abordada a partir de múltiplas perspectivas ou estratégias de pesquisa, as quais focalizam diferentes áreas e fenômenos, como genes, regulação gênica, plasticidade fenotípica, epigenética, morfologia, embriologia, comportamento animal, construção de nicho, estrutura populacional, padrões macroevolutivos, entre outros. Uma miríade considerável de disciplinas da biologia elabora estudos com consequências evolutivas relevantes. Da macroecologia à biologia molecular, esse pluralismo amplia a biologia evolutiva para diferentes níveis de análise, de continentes e ecossistemas à bioquímica da vida.

A complexidade dos sistemas estudados pela biologia evolutiva leva a uma pluralidade de hipóteses causais que não são necessariamente concorrentes com as adotadas pela síntese evolutiva. As evidências empíricas e os avanços teóricos recentes expuseram que, a despeito da grande importância da seleção natural, da extrapolação da microevolução à macroevolução, do gradualismo estrito e do "genecentrismo", é preciso combinar outras conjecturas evolutivas.

Tais domínios amplos e diversificados de pesquisa têm impactos experimentais e teóricos, ampliando a base empírica da teoria evolutiva, aumentando seu poder explicativo e redefinindo conceitos e termos. É provável que essa diversidade tenha impacto sobre a estrutura da própria teoria evolutiva, que já não é a mesma de décadas atrás (Pievani, 2002). Desse modo, surge uma questão crucial: o que exatamente é a biologia evolutiva do século XXI? 
Como vamos argumentar a seguir, a biologia evolutiva contemporânea é mais bem caracterizada como um "pluralismo evolutivo". O pensamento evolutivo tem vivenciado atualmente um momento de reformulações que passa pela proliferação de conceitos, sendo caracterizado por um pluralismo de processos, padrões e hereditariedade na biologia evolutiva (Pigliucci, Kaplan, 2000; Doolittle, Bapteste, 2007; Danchin et al., 2011).

\section{Pluralismo evolutivo}

Tem sido comum entre historiadores e filósofos o posicionamento a favor de um pluralismo na biologia evolutiva (Brigandt, 2010, p.296). Há muitas nuanças sobre o tipo de pluralismo adotado e os seus limites, os quais são dependentes das discussões específicas levadas a cabo.

O pluralismo evolutivo tem sido defendido na literatura com base na descrição da prática científica dos evolucionistas - os quais participam de diferentes disciplinas, adotam diferentes conceitos, métodos, explicações etc. -, mas também com referência à complexidade e à hierarquia dos fenômenos biológicos (Pievani, 2002; Mitchell, 2003; Dieckmann, Doebeli, 2005; Brigandt, 2010). De acordo com essa visão, tanto as tradições de pesquisa entre diferentes biólogos evolutivos quanto os heterogêneos e complexos fenômenos da evolução atuam como justificativas para o pluralismo evolutivo. No primeiro caso, o pluralismo é defendido a partir da descrição da prática científica, assumindo essa prática como legítima. No segundo caso, o pluralismo é defendido sob uma base metafísica, a partir de teses sobre o conteúdo do mundo biológico como um todo (Dupré, 1993). Portanto, o pluralismo evolutivo é fundado tanto no plano da prática e do discurso científico quanto no plano metafísico. Vamos ver a seguir cada um desses fundamentos.

\section{A prática científica como base ao pluralismo evolutivo}

O primeiro grande eixo que baseia o pluralismo evolutivo é a descrição da atividade científica: ou seja, formamos inevitavelmente uma imagem pluralista da teoria evolutiva quando procuramos caracterizá-la nos dias de hoje. Quando olhamos para a própria ciência, vemos um pluralismo de teorias, métodos, programas de pesquisa, tradições de pesquisa, temas científicos, conceitos etc. que são abordados pelos evolucionistas. E essa consideração é endossada tanto pelos cientistas que buscam caracterizar seu campo quanto pelos historiadores da biologia (Pievani, 2002; Mitchell, 2003; Dieckmann, Doebeli, 2005; Brigandt, 2010; Stoltzfus, 2017).

Dessa forma, quando comparamos a síntese evolutiva original e a biologia evolutiva contemporânea, com seus resultados empíricos e teóricos de novas abordagens, chegamos a uma perspectiva pluralista. É nesse sentido que Pievani (2002, p.65) descreve o pluralismo evolutivo de um modo tridimensional: sobre ritmos evolutivos; sobre unidades e níveis evolutivos; e sobre fatores e causas envolvidos na evolução biológica.

Se o gradualismo é considerado um elemento essencial da síntese evolutiva e do próprio darwinismo, os ritmos evolutivos foram ampliados desde a discussão sobre a teoria do equilíbrio pontuado (Gould, Eldredge, 1972). Esses padrões não são mutuamente 
excludentes, uma vez que podem explicar a evolução de diferentes linhagens, compondo um quadro mais pluralista sobre os ritmos evolutivos.

Essa é uma das razões que nos leva a outro tipo de pluralismo - o chamado pluralismo de padrões evolutivos (Doolittle, Bapteste, 2007). Para Doolittle e Bapteste (2007, p.2048), a crença de que a natureza deve exibir um padrão único de relações entre os táxons expõe um monismo de padrão, em oposição ao pluralismo de padrão - o reconhecimento de que variados modelos e representações de relações evolutivas são apropriados e verdadeiros para diferentes táxons. A síntese evolutiva assume um monismo de padrão, representando a história da vida como uma grande árvore com relações hierárquicas bem estabelecidas entre ancestrais e descendentes.

Alguns processos de transmissão horizontal descritos pelos biólogos nos últimos anos nos levam a padrões diferentes do que o representado pela metáfora da árvore. A simbiose, a transferência genética horizontal (preponderante em bactérias), bem como a hibridização entre espécies distintas, resultam em padrões distintos de relações hierárquicas bem estabelecidas entre ancestrais e descendentes. Desse modo, não se trata de negar o padrão em árvore, mas reconhecer que há um pluralismo de padrões que representam a história da vida quando consideramos os mais variados táxons e os processos de transmissão horizontal e vertical (Doolittle, Bapteste, 2007).

A síntese evolutiva também limitou a discussão em relação às unidades de evolução, privilegiando algumas entidades biológicas envolvidas causalmente no processo evolutivo. Nos últimos anos, uma série de biólogos e filósofos tem proposto que genes, organismos e espécies devem ser considerados "indivíduos" biológicos em todos os aspectos e, portanto, sujeitos à seleção. A seleção natural pode ser formulada de forma totalmente abstrata - não envolvendo referência a organismos ou quaisquer outras unidades biológicas. Entidades em muitos níveis da hierarquia biológica podem satisfazer as suas condições - incluindo genes, cromossomos, organelas, células, organismos multicelulares, colônias, grupos e espécies. A natureza hierárquica do mundo biológico, combinada com a abstração do princípio da seleção natural, leva a uma gama de unidades nas quais a seleção pode, em princípio, atuar (Folguera, 2011).

Além disso, alguns debates da biologia evolutiva do desenvolvimento também se deslocam do pensamento populacional, privilegiando o organismo como a preocupação central da evolução. Uma vez que as modificações nos mecanismos do desenvolvimento são centrais para a evolução da forma orgânica, a ontogenia é considerada uma unidade evolutiva fundamental (Amundson, 2005). Desse modo, temos três abordagens distintas sobre as unidades evolutivas e de seleção na biologia evolutiva contemporânea - (1) Pensamento populacional: organismos não evoluem, são as populações que evoluem; organismos ou genes podem ser alvos da seleção natural; (2) Ontogenético: organismos não evoluem. Ontogenias evoluem; características fenotípicas são efeitos da evolução das ontogenias. (3) Macroevolutivo: espécies são alvo de seleção; as espécies constituem uma unidade evolutiva por direito próprio (Amundson, 2005, p.249).

Para que se constitua como uma unidade evolutiva, as mudanças que um nível biológico sofre com o tempo devem se acumular, gerando um duplo jogo de identidade e diferença (Gould, Lloyd, 1999). Dessa forma, um requisito das unidades evolutivas é que elas sejam 
entidades do tipo reprodutivo, permitindo uma continuidade espaçotemporal (Hull, 1976, p.182). Para que a evolução seja cumulativa e persistente, as mudanças realizadas em uma unidade evolutiva devem ser até certo ponto preservadas na geração seguinte. Em relação às mudanças populacionais, essa persistência necessária é garantida pela hereditariedade. E assim como os outros aspectos discutidos até aqui, os biólogos estão cada vez mais apontando para a necessidade de uma concepção mais "inclusiva" de herança, propondo modelos pluralistas de hereditariedade biológica (Danchin et al., 2011; Walsh, 2015).

Como já discutido, a síntese evolutiva possui uma visão denominada "genecentrista", por privilegiar o gene como unidade básica de hereditariedade. A teoria do gene na genética clássica, e adotada na genética de população, nada diz em relação ao modo pelo qual os genes estão ligados causalmente com o produto final, os caracteres. Dessa forma, o estudo da hereditariedade na síntese evolutiva tem como ênfase as causas da transmissão genética entre as gerações (Amundson, 2005).

Esse modelo de hereditariedade tem sido imensamente útil e bem sucedido na biologia evolutiva. Não obstante o seu sucesso explicativo, acumulam-se críticas à descrição da hereditariedade biológica em termos puramente genéticos. Com os estudos sobre biologia molecular, genômica, biologia do desenvolvimento e as pesquisas sobre evolução comportamental e cultural, acumularam-se evidências para a insuficiência explicativa da genética da transmissão como modelo único da hereditariedade biológica (Uller, Helanterä, 2014).

Argumenta-se que mecanismos de herança genética e não genética, assim como as interações entre eles, têm efeitos evolutivos relevantes, podendo ser um importante gatilho para a divergência e especiação, além de desempenhar um importante papel na evolução adaptativa (Laland et al., 2015). Dependendo do autor, a ênfase e a discussão teórica sobre hereditariedade podem ser diferentes. Por exemplo, Eva Jablonka e Marion Lamb (2005) tratam hereditariedade como transferência de informações entre gerações, estabelecendo os sistemas genético, epigenético, comportamental e simbólico. Oyama, Griffiths e Gray (2001), na perspectiva da teoria dos sistemas em desenvolvimento, não encaram a hereditariedade como transmissão de informação por meio de canais discretos (como Jablonka, Lamb e outros), mas enfatizam o processo de reconstrução de ciclos de vida no qual a geração parental contribui. Essas perspectivas sobre a hereditariedade parecem diferentes, e não é óbvio o modo como estão relacionadas. Uma análise detalhada desse tema está além do escopo deste artigo.

Finalmente, em relação aos mecanismos e fatores evolutivos, percebemos que a síntese evolutiva adere a uma visão funcional e adaptacionista. O chamado pluralismo de processos é geralmente pensado em oposição às posições adaptacionistas, centradas na seleção natural (Orzack, Forber, 2017). Dessa forma, em consonância com o pluralismo evolutivo está a profusão de processos evolutivos na literatura nos últimos anos, que se somam àqueles fatores privilegiados pela síntese evolutiva (seleção natural, mutação, deriva genética e fluxo gênico).

Argumenta-se que mecanismos genômicos, ecológicos, ontogenéticos e geológicos precisam ser considerados nas explicações sobre mudanças evolutivas. Assim, somam-se aos mecanismos evolutivos clássicos, a plasticidade fenotípica, vieses do desenvolvimento, 
mecanismos de regulação gênica, construção de nicho, extinção em massa, seleção em múltiplos níveis, simbiogênese, evolvabilidade, auto-organização, entre outros (Almeida, ElHani, 2010; Laland et al., 2015). É importante ressaltar que, com isso, as explicações seletivas não são rechaçadas, mas passam a ser consideradas em conjunto ou sinergisticamente com esses outros processos evolutivos.

É interessante notar como esses processos consideram, além de fatores genéticos, também fatores ecológicos, ontogenéticos e geológicos. O desenvolvimento é responsável pela produção da forma orgânica, influenciando o curso da evolução tanto por produzir inovações morfológicas quanto por restringir as possibilidades de sua origem e modificação. Desse modo, tanto a plasticidade do desenvolvimento tem importância como causa evolutiva - por permitir a origem de novidades evolutivas - quanto a variação fenotípica pode ser restringida pelos processos de desenvolvimento. $\mathrm{O}$ viés do desenvolvimento e a restrição do desenvolvimento ajudam a compreender como algumas formas são mais prováveis de evoluir do que outras, clarificando exemplos de convergência evolutiva (Laland et al., 2015, p.3). Além disso, um entendimento dos processos do desenvolvimento ajuda a explicar mudanças evolutivas complexas, como a evolução dos planos corporais dos animais.

Em relação à dinâmica ecológica, destaca-se que os seres vivos não evoluem para se encaixar em ambientes preexistentes, mas coconstroem e coevoluem com seus ambientes, mudando a estrutura dos ecossistemas. Alguns autores fazem uma crítica de que a síntese evolutiva encara o ambiente como uma "peneira" que determina passivamente aquelas formas que conseguem sobreviver nas populações ao longo do tempo (Reis, 2017). Dessa forma, para autores como Odling-Smee, Laland e Feldman (2003), a construção de nicho - processo pelo qual os organismos modificam ativamente seus próprios nichos e de outros organismos - deve ser reconhecida como um processo evolutivo de direito próprio. Esse processo direciona a evolução pela modificação não aleatória de ambientes seletivos pelos próprios organismos.

Por fim, os eventos geológicos são importantes no entendimento dos processos macroevolutivos, que ocorrem em grande escala de tempo. Eventos de glaciação e deriva continental estão envolvidos na diversificação e extinção de clados. As extinções em massa e extinções de fundo são importantes na macroevolução porque eliminam grupos de determinadas regiões geográficas, estimulando irradiações evolutivas de outros táxons. Esses eventos estocásticos permeiam a história evolutiva das linhagens, alterando-as de tal forma que as taxas de especiação, o aumento de disparidade e as taxas de extinção se alteram. Um exemplo é o soerguimento do istmo do Panamá, que fez com que a América do Norte e a América do Sul se conectassem, possibilitando que muitas linhagens antes endêmicas se dispersassem entre os continentes. Nesse evento, muitas espécies surgiram e outras pereceram (Paes-Neto, Santos, Melo, 2017). Um processo evolutivo relacionado com os eventos geológicos é a seleção de espécie, um tipo de seleção em que as espécies funcionam como indivíduos e apresentam taxas de especiação e extinção de forma análoga à reprodução e sobrevivência da seleção natural clássica. Dessa forma, alguns paleontólogos defendem que os componentes geológicos que alteram as taxas de extinção e especiação são processos evolutivos de direito próprio (Lieberman, Miller, Eldredge, 2007).

Ainda podemos acrescentar na discussão sobre pluralismo evolutivo uma série de conceitos centrais da teoria evolutiva que podem ser tomados em uma perspectiva pluralista. Um deles 
é o pluralismo sobre conceitos de espécies. Mayden (1997), por exemplo, listou 24 diferentes conceitos de espécies. Muitos desses conceitos e suas definições associadas são incompatíveis, na medida em que podem levar a diferenças sobre os limites e números de espécies classificadas.

O conceito de ambiente é outro exemplo que pode ser tomado em uma perspectiva pluralista. O ambiente na abordagem monista da síntese evolutiva é tomado como a pressão seletiva que atua no organismo e que determina as formas que sobrevivem ou se extinguem na competição pela replicação e multiplicação de genes (Dawkins, 1996). Em uma abordagem pluralista, seres vivos e ambiente estão inscritos em um processo interminável de coevolução, no qual diversos caminhos evolutivos interagem: em processos de plasticidade fenotípica, na diferenciação de populações devido a mecanismos de isolamento geográfico, na rápida extinção de espécies por mudanças ambientais, seguida de divergência evolutiva, na "seleção de espécies" em nível macroevolutivo, entre outros (Vrba, 1983).

Não há consenso para muitas das questões que envolvem o pluralismo evolutivo, uma vez que determinados autores consideram que alguns processos podem ser subordinados a outros. Para Caponi (2016), por exemplo, há uma subordinação explicativa da construção de nicho pela seleção natural. A construção de nicho, segundo o autor, não deve ter o estatuto de um mecanismo evolutivo propriamente dito, pois não atua "em paralelo" à seleção natural como um agente evolutivo.

De qualquer forma, ao olharmos para os avanços empíricos e conceituais da biologia evolutiva nos dias de hoje, inevitavelmente temos um quadro pluralista da evolução em relação aos seus principais aspectos. Na próxima seção, vamos discutir como o pluralismo evolutivo também está enraizado em concepções metafísicas.

\section{As bases metafísicas do pluralismo evolutivo}

Os cientistas geralmente têm suposições fortes sobre o mundo que estão investigando, formando uma metafísica anterior (Dupré, 1993). Um exemplo clássico é o de considerar que o mundo material se apresenta como uma espécie de sistema mecânico, tal qual as engrenagens de um mecanismo de relógio. No caso da biologia, uma suposição metafísica que apoia o pluralismo evolutivo concebe o mundo biológico como complexo, multinível e contingente (Mitchell, 2003).

Segundo Sandra Mitchell (2003), os organismos e ecossistemas exibem complexidade constitutiva e processual. A complexidade constitutiva se refere ao todo ser formado de inúmeras partes. A complexidade processual está vinculada a propriedades dinâmicas da vida, como a sensibilidade extrema às condições iniciais, auto-organização e feedbacks negativos e positivos. Uma vez que é impossível abordar todos esses elementos complexos simultaneamente, as abordagens de pesquisa devem inevitavelmente selecionar aspectos da complexidade biológica a abordar. Cada seleção constitui uma análise diferente do universo causal, criando diferentes conjuntos efetivos de causas alternativas. As explicações que são levantadas na exploração científica dessa diversidade do mundo biológico acabam gerando parte do pluralismo evolutivo (Mitchell, 2003, p.115).

Se esse é o caso, isto é, se a natureza do mundo biológico é tal que fenômenos importantes não podem ser completa e exaustivamente explicados com base em um único conjunto de 
princípios fundamentais, então os objetivos, métodos e resultados da biologia não devem ser entendidos ou avaliados em referência a uma busca monista. Diferentes abordagens são apropriadas para os objetivos pragmáticos e conceituais da biologia. Dessa forma, os tipos de conhecimento e os próprios métodos que usamos para estudar os sistemas biológicos acabam refletindo essa complexidade (Kellert, Longino, Waters, 2006).

Outra base metafísica do pluralismo evolutivo assume que a evolução envolve processos que ocorrem em múltiplos níveis de organização (Mayr, 1961; Sherman, 1988). As pesquisas evolutivas têm como foco processos em diferentes níveis, que estão sujeitos a diferentes fatores evolutivos e não podem ser colapsados em um só (Kellert, Longino, Waters, 2006). Uma imagem simples e unificada da biologia evolutiva seria inadequada para tratar os sistemas complexos, multicomponentes e de múltiplos níveis que povoam o domínio dos seres vivos. As pesquisas com múltiplos processos causais e tipos de explicações oferecidas para os fenômenos evolutivos nos níveis molecular, morfológico, comportamental, ecológico, geológico etc. acabam gerando as formas de pluralismo explicativo e metodológico na biologia contemporânea (Mitchell, 2003).

Finalmente, a chamada tese da contingência evolutiva também é uma base metafísica do pluralismo evolutivo. Como Stephen Jay Gould disse certa vez, a evolução é como um videoteipe que, se repetido várias vezes, teria um final diferente a cada vez. Beatty (1995, p.221) amplia a tese de Gould para defender que a contingência evolutiva não apenas cria regularidades na natureza, mas também "quebra as regras" do mundo vivo. Por exemplo, a chamada lei de Hardy-Weinberg, um dos princípios centrais da biologia evolutiva, é uma consequência dedutiva da primeira lei de Mendel. Essa lei estabelece que as características dos indivíduos são condicionadas por pares de fatores (genes) que se separam durante a formação dos gametas, indo apenas um fator do par para cada gameta. A primeira lei de Mendel e, por consequência, a lei de Hardy-Weinberg, são decorrentes do mecanismo meiótico de segregação de gametas na reprodução sexual.

A meiose, como qualquer outro processo biológico, não deixa de ser um produto evolutivo (Beatty, 1995). Isso significa que as generalizações biológicas obtidas a partir desse mecanismo - a primeira lei de Mendel e a lei de Hardy-Weinberg - são evolutivamente contingentes, e, portanto, não são leis da natureza nem uma necessidade natural. Explorando o exemplo de Gould, se voltássemos à história da vida, não haveria uma necessidade de a evolução ter resultado no mecanismo de meiose e na segregação de gametas na proporção esperada pela lei de Mendel em organismos sexuados.

Para Beatty (1995, p.229), o fato de as contingências da história evolutiva impedirem a existência de leis na biologia força os biólogos a ser pluralistas teóricos. O pluralismo teórico contrasta com o ideal de explicar um domínio de fenômenos em termos de um número pequeno de mecanismos gerais. Esse ideal foi particularmente adotado pela física newtoniana, um exemplar de ciência para muitos arquitetos da síntese evolutiva (Smocovitis, 1996). Os modelos de mudança evolutiva foram construídos com base nos modelos da física, de modo a demonstrar que a evolução possui regularidades semelhantes às leis físicas. Na síntese evolutiva, essa inspiração foi fundamentada na genética e, em última análise, no princípio matemático do equilíbrio de Hardy-Weinberg, que teria uma abrangência explicativa para diferentes níveis biológicos. 
A recusa de explicar a evolução em termos de um número pequeno de mecanismos também é baseada na compreensão de que a vida é essencialmente heterogênea. Dependendo do grupo de organismos, a evolução pode ter criado regularidades que levaram a diferentes processos evolutivos, mecanismos de herança e padrões evolutivos. Por isso, uma extensão da tese da contingência é que não existe uma teoria ou mecanismo único - nem mesmo uma teoria ou grande síntese multicausal - que seja responsável por todas as explicações do domínio evolutivo (Beatty, 1995). Outra consequência dessa tese é a de que praticamente todas as disciplinas biológicas podem contribuir para a compreensão da evolução. Isso ocorre porque, ao investigar o funcionamento de determinado grupo de organismo ou nível biológico, uma disciplina pode contribuir para o entendimento de processos, padrões evolutivos e mecanismos de herança. Dessa forma, embriologia, paleontologia, ecologia, botânica, zoologia, microbiologia, entre outras disciplinas da biologia, podem elucidar questões genuinamente evolutivas.

\section{A questão da unidade na biologia}

Os pluralistas precisam responder a questões difíceis, particularmente oriundas da filosofia da ciência. Um dos desafios apresentados é de que uma postura pluralista implicaria que as abordagens e teorias científicas não fornecem uma única verdade completa e abrangente para o domínio evolutivo. Na ausência de padrões fundamentais de justificação, toda e qualquer forma de argumentação seria aceitável. Desse modo, algumas versões pluralistas poderiam promover um vale-tudo na biologia, pelo menos no que diz respeito à verdade e à demarcação científica (Boghossian, 2012).

Alguns defensores do pluralismo evolutivo buscam distinguir a sua postura pluralista do relativismo e estabelecer critérios mínimos de demarcação na ciência. Em uma perspectiva relativista, haveria a negação de restrições objetivas ao pluralismo evolutivo, podendo fazer parte desse pluralismo e em pé de igualdade o criacionismo e o design inteligente, por exemplo. Uma forma de colocar restrições razoáveis sobre quais tipos de conhecimentos científicos são admissíveis é se voltar para virtudes epistêmicas que as teorias biológicas possuem. Existem muitas virtudes possíveis e reais, como sensibilidade a fatos empíricos, pressupostos de fundo plausíveis, coerência com outros conhecimentos, exposição a críticas da mais ampla variedade de fontes, entre outros (Dupré, 1993).

Outra crítica ao pluralismo evolutivo é a ausência de relação entre as teorias e disciplinas biológicas (Mitchell, 2003). Um pluralista poderia reconhecer que diferentes tipos de questões requerem respostas diferentes, e, portanto, não haverá interação entre os cientistas que trabalham com diferentes níveis. Em um caso extremo, pode levar a uma forma de isolamento dentro do domínio evolutivo. O problema com esse quadro é que ele pressupõe o fechamento explicativo dentro de cada nível de análise e uma estreiteza no escopo da investigação científica que impede o tipo de interações frutíferas entre disciplinas e teorias, as quais caracterizam grande parte da história da ciência (Mitchell, 2003).

Um problema adicional é que, quando analisamos as pesquisas em diferentes níveis de investigação, podemos ver que em muitos casos elas não podem ser satisfatoriamente 
tratadas sem considerar outros níveis. Mesmo quando ocorre uma situação improvável, em que um cientista está estritamente preocupado com apenas um nível de análise, seria um erro pensar que as respostas a outras perguntas não têm relação com a investigação nesse nível. Por isso, muitas das discussões que argumentam a favor do pluralismo deixaram um vácuo filosófico, na medida em que elas não buscam a questão de como diferentes campos, métodos e conceitos estão relacionados na prática biológica, ou então como eles podem ser integrados (Brigandt, 2010, p.296).

Segundo Kellert, Longino e Waters (2006), uma postura pluralista não rejeita imediatamente os esforços de integração, mas recusa-se a supor que a unidade seja sempre possível ou a síntese seja um fim em si. O pluralismo não pressupõe que todas as disciplinas sejam comensuráveis e, em última análise, unificáveis, tampouco presume que cada disciplina seja necessariamente isolada e incomensurável com as outras. O pluralismo defendido por Kellert, Longino e Waters (2006) sustenta que, para quaisquer disciplinas, é uma questão contingente e aberta se elas podem ou devem ser unidas ou integradas. Tais questões devem ser respondidas caso a caso. Para alguns problemas, uma abordagem multidisciplinar de cooperação parece ocorrer, ao passo que outros problemas parecem fomentar a criação de uma nova disciplina. Mas os pluralistas sustentam que não há boas razões para presumir que isolamento, cooperação, integração ou síntese sejam bons em todos os casos.

Contra um pluralismo que simplesmente afirma que a biologia precisa de uma diversidade de disciplinas e abordagens teóricas, alguns autores argumentam que resolver problemas biológicos complexos (atendendo a alguns objetivos explicativos ou epistêmicos) requer pelo menos a integração parcial de conceitos e explicações de diferentes campos. Esse é o caso de autores como Darden e Maull (1977), Sandra Mitchell (2003), Ingo Brigandt (2010), Telmo Pievani (2016), entre outros.

Darden e Maull (1977) argumentam que a motivação para a integração na biologia é, na maioria das vezes, a existência de um problema científico que não pode ser resolvido por um campo de pesquisa isolado. Quando pesquisadores reconhecem que possuem interesses em comum, a integração entre diferentes campos pode resultar da origem do que elas chamam de "teoria intercampos". Outro exemplo nessa linha é o "pluralismo integrativo" (integrative pluralism) de Sandra Mitchell (2003). O pluralismo integrativo visaria incorporar diferentes níveis de análise pelo estabelecimento de pequenas integrações "locais". A autora argumenta que o pluralismo integrativo é a melhor descrição da complexidade evolutiva, multicomponente e de variados níveis dos sistemas biológicos. A complexidade, em sua opinião, invoca múltiplos níveis de organização e múltiplos fatores causais, que requerem uma integração de abordagens para exaurir os problemas biológicos. É um tipo de integração necessário para explicar fenômenos complexos, mas sem uma unificação em larga escala.

Mais recentemente, Brigandt (2010) discute uma proposta de integração que pode ser efetuada por unidades epistêmicas menores (como conceitos, métodos, explicações), vinculadas segundo problemas científicos específicos. Enquanto uma síntese/unificação é uma conexão estável de disciplinas, no modelo flexível de Ingo Brigandt uma disciplina pode manter sua independência e identidade tradicional, mas entrar em relações mais transitórias com outros campos, dependendo de qual problema for abordado. 
A proposta de Brigandt (2010) é fundamentada na história da ciência e em um exemplo específico da biologia evolutiva, a saber, as explicações sobre a origem das novidades evolutivas. Segundo o autor, uma disciplina única não é suficiente para resolver os problemas relacionados com a origem de grandes novidades evolutivas, e muitas das soluções encontradas na história da biologia exigiram o envolvimento de diferentes campos. Exemplos de novidades evolutivas são as mandíbulas dos vertebrados e a evolução das penas nas aves, as quais levaram ao envolvimento dos campos da filogenia, paleontologia, ecologia, biogeografia e biologia do desenvolvimento para sua elucidação. Dessa forma, o autor sugere que resolver problemas complexos, como os encontrados na biologia evolutiva, não requer uma síntese estável de diferentes campos biológicos, mas integrações de unidades epistêmicas menores, visando solucionar problemas específicos (Brigandt, 2010, p.297).

Finalmente, Telmo Pievani (2016) defende que uma abordagem construída a partir da interação entre múltiplos níveis de mudanças evolutivas - desde os microníveis genéticos até os macroníveis geológicos - pode ser a base de uma proposta "metateórica" na biologia evolutiva. Baseado na teoria hierárquica de Niles Eldredge (1985), o autor acredita que as pesquisas em vários níveis e unidades biológicas não deveriam ser tomadas como um sinal de desunificação, mas como uma importante oportunidade para a integração teórica na biologia evolutiva (Pievani, 2016, p.454).

\section{Considerações finais}

Como discutido ao longo do artigo, a síntese evolutiva apresentou um amplo projeto de unificação da biologia. No entanto, alguns sinais visíveis das limitações desse ideal apareceram pouco tempo após a sua consolidação. A biologia evolutiva contemporânea compreende múltiplos quadros conceituais coexistentes e perspectivas que discordam sobre a natureza e o escopo da teoria evolutiva. O pensamento evolutivo tem vivenciado atualmente um momento de reformulações que passa pela proliferação de abordagens, conceitos e processos, sendo caracterizado por um pluralismo evolutivo.

Desse modo, quando olhamos para a prática científica não encontramos uma ampla síntese na biologia, mas uma série de integrações que não envolvem uma unificação estável dos diferentes campos biológicos. As formas de integração encontradas podem ser compatíveis com uma postura pluralista, sem o recurso às visões mais tradicionais de unidade da ciência. Unificação não é um objetivo em si na perspectiva do pluralismo evolutivo, mas integrações locais ocorrem e devem ocorrer na biologia para finalidades epistêmicas específicas. Nossa crítica é endereçada à suposta ampla unificação da biologia como um todo a partir da evolução biológica.

\section{NOTA}

${ }^{1}$ Embora as críticas de Gould e Lewontin carreguem prestígio acadêmico, a discussão sobre o programa adaptacionista continua em voga. Mais recentemente, Godfrey-Smith (2001) oferece uma visão geral do adaptacionismo e o distingue em três versões (empírico, explanatório e metodológico), cada uma com diferentes usos na biologia evolutiva contemporânea. 


\section{REFERÊNCIAS}

ABRANTES, Paulo Cesar Coelho. Introdução: o que é filosofia da biologia? In: Abrantes, Paulo Cesar Coelho (org.). Filosofia da biologia. Porto Alegre: Artmed, 2011. p.11-36.

ALMEIDA, Ana Maria Rocha; EL-HANI, Charbel Niño. Um exame histórico-filosófico da biologia evolutiva do desenvolvimento. Scientiae Studia, v.8, n.1, p.9-40, 2010.

AMUNDSON, Ronald. The changing role of the embryo in evolutionary thought: roots of evo-devo. Cambridge: Cambridge University Press, 2005.

BEATTY, John. The evolutionary contingency thesis. In: Wolters, Gereon; Lennox, James (ed.). Theories and rationality in the biological sciences. The Second Annual Pittsburgh/Konstanz Colloquium in the Philosophy of Science, University of Pittsburgh Press, 1995. p.45-81.

BOGHOSSIAN, Paul. Medo do conhecimento: contra o relativismo e o construtivismo. São Paulo: Editora Senac, 2012.

BRIGANDT, Ingo. Beyond reduction and pluralism: toward an epistemology of explanatory integration in biology. Erkenntnis, v.73, n.3, p.295-311, 2010.

CAPONI, Gustavo. Subordinación explicativa de la construcción de nichos a la selección natural. Filosofia e História da Biologia, v.11, n.2, p.203220, 2016.

CUNHA, Ivan Ferreira. Círculo de Viena: fisicalismo e a utopia da ciência unificada. Educação e Filosofia, v.32, n.66, p.943-963, 2018.

DANCHIN, Étienne et al. Beyond DNA: integrating inclusive inheritance into an extended theory of evolution. Nature Reviews Genetics, v.12, n.7, p.475-486, 2011.

DARDEN, Lindley; MAULL, Nancy. Interfield theories. Philosophy of Science, v.44, n.1, p.43-64, 1977.

DAWKINS, Richard. The blind watchmaker: why the evidence of evolution reveals a universe without design. New York: Norton \& Company, 1996.

DELISLE, Richard. What was really synthesized during the evolutionary synthesis? A historiographic proposal. Studies in History and Philosophy of Biological and Biomedical Sciences, v.42, n.1, p.50-59, 2011.

DIECKMANN, Ulf; DOEBELI, Michael. Pluralism in evolutionary theory. Journal of Evolutionary Biology, v.18, n.5, p.1209-1213, 2005.

DOOlitTlE, W. Ford; BAPTESTE, Eric. Pattern pluralism and the tree of life hypothesis.
Proceedings of the National Academy of Sciences, v.104, n.7, p.2043-2049, 2007.

DUPRÉ, John. The disorder of things: metaphysical foundations of the disunity of science. Cambridge, Massachusetts: Harvard University Press. 1993.

ELDREDGE, Niles. Unfinished synthesis: biological hierarchies and modern evolutionary theory. Oxford: Oxford University Press, 1985.

FÁBREGAS-TEJEDA, Alejandro; VERGARASILVA, Francisco. Hierarchy theory of evolution and the extended evolutionary synthesis: some epistemic bridges, some conceptual rifts. Evolutionary Biology, v.45, n.2, p.127-139, 2018.

FERREIRA, Marcia Serra; SELLES, Sandra Escovedo. Entrelaçamentos históricos das ciências biológicas com a disciplina escolar biologia: investigando a versão azul do BSCS. In: Encontro Nacional de Pesquisa em Educação em Ciências, 5., 2005, Bauru. Atas... Bauru: Abrapec, 2005.

FOLGUERA, Guillermo. Filosofía de la biología: análisis crítico de las jerarquías en la teoría de la evolución. Madrid: EAE Editorial Academia Espanola, 2011.

FUTUYMA, Douglas J. Evolutionary biology today and the call for an extended synthesis. Interface focus, v.7, n.5, p.20160145, 2017.

GODFREY-SMITH, Peter. Three kinds of adaptationism. In: Orzack, Steven H.; Sober, Elliot (ed.). Adaptationism and optimality. Cambridge: Cambridge University Press, 2001. p.335-357.

GOULD, Stephen Jay. The hardening of the modern synthesis. In: Grene, Marjorie (ed.). Dimensions of darwinism. Cambridge: Cambridge University Press, 1983. p.71-93.

GOULD, Stephen Jay. Is a new and general theory of evolution emerging? Paleobiology, v.6, n.1, p.119-130, 1980.

GOULD, Stephen Jay; ELDREDGE, Niles. Punctuated equilibria: an alternative to phyletic gradualism. In: Schopf, Thomas J.M. (ed.). Models in paleobiology. San Francisco: Freeman, Cooper and Company, 1972. p.82-115.

GOULD, Stephen Jay; LEWONTIN, Richard. The spandrels of San Marco and the Panglossian paradigm: a critique of the adaptationist programme. Proceedings of the Royal Society of London B, v.205, n.1161, p.581-598, 1979.

GOULD, Stephen Jay; LLOYD, Elisabeth. Individuality and adaptation across levels of 
selection: how shall we name and generalize the unit of Darwinism? Proceedings of the National Academy of Sciences of the United States of America, v.96, n.21, p.11904-11909, 1999.

HAHN, Hans; NEURATH, Otto; CARNAP, Rudolf. A concepção científica do mundo - o círculo de Viena: dedicado a Moritz Schlick. Cadernos de História e Filosofia da Ciência, v.10, n.1, p.5-20, 1986.

HULL, David. Are species really individuals? Systematic Zoology, v.25, n.2, p.174-191, 1976.

JABLONKA, Eva; LAMB, Marion. Evolution in four dimensions: genetic, epigenetic, behavioral and symbolic variation in the history of life. Cambridge: MIT Press, 2005.

KELLERT, Stephen; LONGINO, Helen; WATERS, C. Kenneth (ed.). Scientific pluralism. Minneapolis: Minnesota Press, 2006.

KIMURA, Motoo. Neutral theory of molecular evolution. Nature, v.217, p.624-626, 1968.

LALAND, Kevin N. et al. The extended evolutionary synthesis: its structure, assumptions and predictions. Proceedings of the Royal Society of London Series B, v.282, n.1813, p.20151019, 2015.

LALAND, Kevin N. et al. Does evolutionary theory need a rethink? Nature News, v.514, n.7521, p.161-164, 2014.

LARGENT, Mark. The so-called eclipse of Darwinism. In: Cain, Joe; Ruse, Michael (ed.). Descended from Darwin. Philadelphia: American Philosophical Society, 2009. p.3-21.

LIEBERMAN, Bruce S; MILLER, William; ELDREDGE, Niles. Paleontological patterns, macroecological dynamics and the evolutionary process. Evolutionary Biology, v.34, n.1-2, p.2848, 2007.

MAYDEN, Richard. A hierarchy of species concepts: the denouement in the saga of the species problem. In: Claridge, Michael; Dawah, Hassan A.; Wilson, Michael R. (ed.). Species: the units of biodiversity. London: Chapman and Hall, 1997.

MAYR, Ernst. Some thoughts on the history of the evolutionary synthesis. In: Mayr, Ernst; Provine, William (ed.). The evolutionary synthesis: perspectives on the unification of biology. Cambridge, MA: Harvard University Press, 1980. p.1-48.

MAYR, Ernst. Cause and effect in biology. Science, v.134, n.3489, p.1501-1506, 1961.

MITCHELL, Sandra. Biological complexity and integrative pluralism. Cambridge: Cambridge University Press, 2003.
ODLING-SMEE, John; LALAND, Kevin; FELDMAN, Marcus. Niche construction: the neglected process in evolution. Princeton: Princeton University Press, 2003.

ORZACK, Steven Hecht; FORBER, Patrick. Adaptationism. The Stanford Encyclopedia of Philosophy, 2017. Disponível em: plato.stanford. edu/archives/spr2017/entries/adaptationism. Acesso em: 20 fev. 2019.

OYAMA, Susan; GRIFFITHS, Paul; GRAY, Russel. Cycles of contingency: developmental systems and evolution. Cambridge, Massachusetts: MIT Press, 2001.

PAES-NETO, Voltaire Dutra; SANTOS, Marcel Baêta Lacerda; MELO, Tomaz Panceri. Palentologia e evolução no tempo profundo. In: Araújo, Leonardo Augusto Luvison (ed.). Evolução biológica: da pesquisa ao ensino. Porto Alegre: Editora Fi, 2017. p.35-60.

PIEVANI, Telmo. How to rethink evolutionary theory: a plurality of evolutionary patterns. Evolutionary Biology, v.43, n.4, p.446-455, 2016.

PIEVANI, Telmo. Rhapsodic evolution: essay on exaptation and evolutionary pluralism. World Futures: The Journal of General Evolution, v.59, n.2, p.63-81, 2002.

PIGLIUCCI, Massimo; KAPLAN, Jonathan. The fall and rise of Dr. Pangloss: Adaptationism and the Spandrels paper 20 years later. Trends in Ecology and Evolution, v.15, n.2, p.66-70, 2000.

PIGLIUCCI, Massimo; MÜLLER, Gerd B. Evolution: the extended synthesis. Cambridge, Mass: MIT Press, 2010.

PROVINE, William. The origins of theoretical population genetics. Chicago: University of Chicago Press, 2001.

PROVINE, William. Progress in evolution and meaning of life. In: Waters, C. Kenneth; Van Helden, Alberts (ed.). Julian Huxley, biologist and statesman of science. Houston: Rice University Press, 1992. p.165-180.

REID, Robert G.B. Evolutionary theory: the unfinished synthesis. Ithaca: Cornell University Press, 1985.

REIS, Claudio Ricardo Martins. Ecologia e evolução: a abordagem evolutiva em livros didáticos de ecologia. In: Araújo, Leonardo Augusto Luvison (ed.). Evolução biológica: da pesquisa ao ensino. Porto Alegre: Editora Fi, 2017. p.391-386.

SARKAR, Sahotra. Haldane's The causes of evolution and the modern synthesis in evolutionary biology. Journal of Genetics, v.96, n.5, p.753-763, 2017. 
SARKAR, Sahotra. Evolutionary theory in the 1920s: the nature of the "synthesis". Philosophy of Science, v.71, n.5, p.1215-1226, 2004.

SHERMAN, Paul W. The levels of analysis. Animal Behaviour, v.36, n.2, p.616-619, 1988.

SMOCOVITIS, Vassiliki Betty. Unifying biology: the evolutionary synthesis and evolutionary biology. Princeton: Princeton University Press, 1996.

SMOCOVITIS, Vassiliki Betty. Unifying biology: the evolutionary synthesis and evolutionary biology. Journal of the History of Biology, v.25, n.1, p.1-65, 1992.

STOLTZFUS, Arlin. Why we don't want another "synthesis". Biology Direct, v.12, n.23, p.1-12, 2017.
ULLER, Tobias; HELANTERÄ, Heikki. Heredity in evolutionary theory. In: Huneman, Philippe; Walsh, Denis (ed.). Challenges to evolutionary biology: development and heredity. Oxford: Oxford University Press, 2014.

VOLTAIRE. Cândido ou o otimismo. Tradução, notas e posfácio de Rui Tavares e ilustração de Vera Tavares. Lisboa: Tinta-da-China, 2006.

VRBA, Elisabeth. Macroevolutionary trends: new perspectives on the roles of adaptation and incidental effect. Science, v.221, n.4608, p.387389, 1983.

WALSH, Denis. Organisms, agency, and evolution. Cambridge: Cambridge University Press, 2015. 